\title{
PRELIMINARY ANALYSIS OF DIFFERENT COOLING SYSTEMS OF SOWS IN FARROWING ROOM
}

\author{
Matteo Barbari, Martina Bianchi, Francesco Sorbetti Guerri
}

\section{Introduction}

Farrowing sows are very sensible to high temperatures, especially in wet regions. In North of Italy the temperatures reach high peaks during summer and the sows can risk death. In lactating sows, heat stress reduces feed intake, increases lactation weight loss and depresses piglets weight gains [14]. Heat stress also may reduce the expression of oestrus after weaning [4]. It is important to remark the serious discomfort conditions of the animals, closed inside a farrowing crate where they are unable to protect themselves from the effects of the heat. This is a real problem especially in the farrowing rooms with plastic floorings, widespread in the last years [2]. Sows do not sweat to dissipate heat, but evaporation from their body surface occurs more by diffusion through the outer skin layers than by evaporation from skin surface [6]. In the last years in Po Plain (North of Italy) the problem of the heat was heavily felt by the breeders during the months of June 2002 and 2003, when temperatures reached very high peaks.

Drip cooling and snout cooling are the systems currently used in the swine housing. The drip method allows refreshing of the sows thanks to a slow and constant release of water in the neck zone. The water evaporation in this area of the body induces a reduction of rectal temperature, improving animal thermal conditions. In Italy this system has been known for many years [1], but it is not widespread. Water drip is an effective cooling technique, for heat stressed sows,

Paper received 18.01.2006; accepted 20.09.2006

Prof. MATTEO BARBARI, matteo.barbari@unifi.it, full professor; Dr. MARTINA BIANCHI, martina.bianchi@unifi.it, phd student; Prof. FRANCESCO SORBETTI GUERRI, francesco.sorbettiguerri@unifi.it, associate professor, Department of Agricultural and Forestry Engineering, University of Firenze.

Research carried out with financial support of Italian Ministry of Education and University (MIUR, Cofin 2003). Dr. Bianchi has taken part to data processing; Prof. Sorbetti Guerri has taken part to planning of research activities and to realization of experimental equipment; Prof. Matteo Barbari is the scientific responsible of the project, has taken part to all the phases of the research and has written the present paper. especially when floors are in plastic materials [11]. Literature shows a water use in range of $2-4 \mathrm{l} / \mathrm{h}$. If electronically controlled, the system works when the temperature rises above a threshold temperature.

With the snout cooling system cooled air is delivered to the head of the sow. Researchers found that the zone cooling of lactating sows reduced respiration rate, increased sow feed consumption, increased litter weight gain and decreased sow weight loss during lactation $[8,12]$. By literature the suggested air flow on the head of the sow is generally considered about $120 \mathrm{~m}^{3} / \mathrm{h}$. In some cases conditioned air is used to cool the snout of the sows, but this system is not suitable for Italy, owing to the high energy costs.

The conductive cool pad is so effective at dissipating heat that only a relatively small contact surface area is needed to maintain the animal's comfort [3]. Therefore also a full steel sheet placed under the body of the sow could give benefit. It can be coupled to drip cooling: thanks to the drip of water that falls on it, the surface remains wet for a long period, keeping the animals cool.

The experience gained during last years, pointed out that the drip cooling system is not enough to assure thermal comfort conditions to the sows, especially when they are lodged on plastic floor, only with natural ventilation systems. In such a situation drip cooling systems have to be coupled with other ones. Comparative evaluation studies of cooling systems for sows in farrowing houses were carried out by different researchers in last years $[5,7,13]$.

\section{Materials and methods}

In a pig farm located in Po Valley an experimental farrowing room was chosen to set the trials. The farrowing room had 16 crates. Each crate was $2.50 \mathrm{~m}$ long, $1.45 \mathrm{~m}$ wide. The cage of the sow was placed diagonally in the crate. The flooring was completely slatted, in plastic material. The tests were carried out during summer 2004 (from 12 June to 15 September). In the farrowing room three different cooling solutions were compared during three different cycles. 
D. Drip cooling system. It was installed in five crates. In each crate there was a drip nozzle, able to supply $2 \mathrm{l} / \mathrm{h}$. The pipe with drip nozzles was suspended above the cage, $0.60 \mathrm{~m}$ from the front of the crate. In this way the lying sow received the drops mainly on the neck. The drip cooling system started four times a day $(0200 \mathrm{~h}$; $0800 \mathrm{~h} ; 1400 \mathrm{~h} ; 2000 \mathrm{~h}$ ) and worked for $30 \mathrm{~min}$.

D-S. Snout cooling system. It was arranged in six crates coupled with drip cooling system. It was realized with a centrifugal fan connected with a duct made of PVC pipes with an internal diameter of $100 \mathrm{~mm}$; the circular hole for air outlet was $66 \mathrm{~mm}$ across. The air was directed close to the head of the sow, under the trough, with a flow of $88 \mathrm{~m}^{3} / \mathrm{h}$ and a constant velocity of 7.2 $\mathrm{m} / \mathrm{s}$. The air could flow over the lying sows, towards either the snout or the neck.

D-F. Full steel sheet. In addition to drip cooling system five crates were provided with full steel sheets of $4 \mathrm{~mm}$ thickness. The pad dimensions changed during the trial: from $2 \mathrm{~m}$ long in the first cycle, to $1.50 \mathrm{~m}$ in the second cycle and to $0.50 \mathrm{~m}$ in the third. The plate remained steady $0.60 \mathrm{~m}$ wide.

A data logger with probes was installed: outside air temperature, inside air temperature, inside radiant temperature and inside relative humidity were continuously recorded. Also manual measures were made with an electronic thermometer for the body rectal temperatures. Skin temperature was measured with an infrared thermometer at $0.20 \mathrm{~m}$ from the tail junction.

At the beginning and at the end of each cycle sows were subjected to the measures of fat thickness in position P2. At the same time the BCS (Body Condition Score) was evaluated by a veterinarian.

Starting from the second cycle, the behaviour of the sows was continuously recorded by two infra-red cameras linked to a time lapse videotape. The behaviour of the three sows (A2, B2, C2 and A3, B3, C3) placed in three consecutive crates was simultaneously monitored. The first crate (identified with number 1) had only the drip cooling system, the second and the third (identified with numbers 2 and 3 ) had both the drip cooling and the snout cooling systems. The be-

\begin{tabular}{lclc}
\hline sow & crate & \multicolumn{1}{c}{ cooling system } & cycle \\
\hline A2 & 1 & drip cooling & II \\
B2 & 2 & drip and snout cooling & II \\
C2 & 3 & drip and snout cooling & II \\
\hline A3 & 1 & drip cooling & III \\
B3 & 2 & drip and snout cooling & III \\
C3 & 3 & drip and snout cooling & III \\
\hline
\end{tabular}

TABLE 1 - Sows evaluated during the second and the third video recording cycle.

\begin{tabular}{|c|c|}
\hline $\begin{array}{l}\text { Lying } \\
\text { abead }\end{array}$ & $\begin{array}{l}\text { The sow lies in the crate, on lateral or sternal } \\
\text { recumbency, with the head placed under the } \\
\text { trough. In this position the nose is close to the } \\
\text { partition of the cage allowing the animal to } \\
\text { benefit from the fresh air coming from the } \\
\text { snout cooling system. }\end{array}$ \\
\hline $\begin{array}{l}\text { Lying } \\
\text { back }\end{array}$ & $\begin{array}{l}\text { The sow lies in a rear position on lateral or } \\
\text { sternal recumbency; in this way she can not } \\
\text { profit from the air that blows from the fan. }\end{array}$ \\
\hline Nursing & $\begin{array}{l}\text { The sow lies on lateral recumbency. A } \\
\text { minimum of } 80 \% \text { of piglets of the litter is } \\
\text { actively nursing or nosing at the udder of the } \\
\text { sow. }\end{array}$ \\
\hline Standing & $\begin{array}{l}\text { The animal stands on four limbs and does not } \\
\text { perform any activity. The sow stands mainly } \\
\text { when eating, drinking, urinating, defecating as } \\
\text { well as when changing position in the cage. }\end{array}$ \\
\hline Sitting & $\begin{array}{l}\text { The trunk of the animal is in contact with the } \\
\text { ground and supports most of the body weight. } \\
\text { The sow sits down for short periods, before } \\
\text { standing or lying. }\end{array}$ \\
\hline $\begin{array}{l}\text { Feeding } \\
\text { /drinking }\end{array}$ & $\begin{array}{l}\text { The head of the sow is inside the trough or at } \\
\text { the nipple drinker. The recorded data do not } \\
\text { allow to understand if the sow is feeding or } \\
\text { drinking. }\end{array}$ \\
\hline
\end{tabular}

TABLE 2 - Recorded behavioural patterns of the sows.

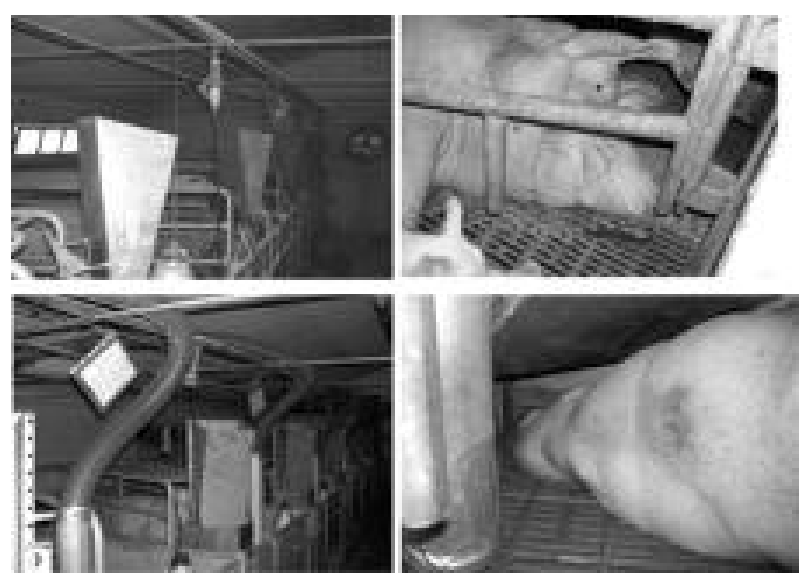

Fig. 1 - The 3 different cooling systems. The pipe of the drip cooling system (top left); the full steel sheet placed under the head of the sow (top right); the pipes of snout system (bottom left); the air coming out from the hole on air pipe (bottom right).

havioural analysis concerned the period from four to eight days after farrowing and from 10 to 20 days after farrowing. In table 1 the details of the trials are summarised.

During the video camera data processing, some activities of the sows were taken into account. They are described in table 2.

Relationships between temperature and relative humidity were established by THI (Temperature Humidity Index), thus allowing to individuate the heat stress periods for pigs. The index used in this trial was based on the deep body temperature of the animals as measure of physiological stress [9]. The original THI formula is:

$$
\mathrm{THI}=0.63 \mathrm{tw}+1.17 \mathrm{td}+32
$$




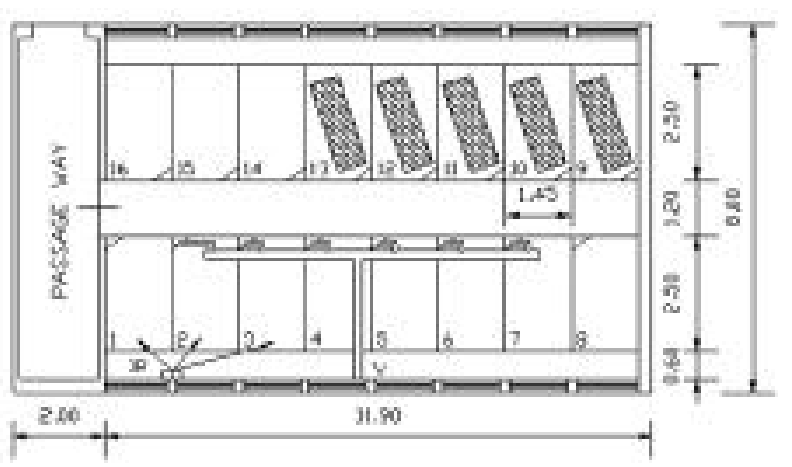

Fig. 2 - The experimental farrowing room. Video cameras are placed near crates 1, 2, 3 and are provided with infrared lamps (IR). The fan (V) takes ventilation air from outside.

where tw and td are the wet and the dry bulb temperatures of the ambient air in ${ }^{\circ} \mathrm{C}$.

A scale of indices indicates the effects of different combinations of temperature and humidity on livestock. The scale is divided into three ranges: THI over 75 indicates an alert situation; THI from 79 to 83 indicates a dangerous condition, and THI over 84 indicates an emergency situation [10]. For the observed periods of the trial, the THI index was evaluated to be compared with the behaviour of the sows.

\section{Results and discussion}

The behavioural data collected by the TV equipment are shown in table 3 . In this table the main results obtained by the video-analysis during the second and the third cycle of observations are summarised. In the two examined periods (25-27 July, 4-6 September) the climatic conditions were very similar and not excessively high (daily average inside air temperature was $26.21{ }^{\circ} \mathrm{C}$; daily average inside air temperature from $0200 \mathrm{~h}$ to $2000 \mathrm{~h}$ was $28.72^{\circ} \mathrm{C}$ ).

It is clear that the sows without snout cooling system have no preferences for lying position; in fact, while sow A2 lies ahead only for the $49.96 \%$ of the total time, sow A3 spends most of her time in this position. On the contrary sows B2, C2 and B3, C3 spend on average the $75.5 \%$ of their time lying ahead with the snout placed under the trough, in a position that allows them to profit from the fresh air flowing from the air pipe. The behaviour of the sows is less clear during the third cycle when also sow A3 lies ahead and sows B3 and C3 sometimes settle themselves in a position that does not allow them to receive the cool air. The two sows lye without air about $13 \%$ of time and profiting of the air on the snout about $70 \%$ of time.

The behavioural analysis allows to conclude that in a cage without the snout cooling system the choice between lying ahead or back is probably indifferent and very subjective for the animals. But in a cage with availability of fresh air it is rather clear that sows stand with the head near the air outlet hole especially when the inside temperature rises. Thanks to a suitable length of the crate sows can choose the best position for lying down, according with the microclimatic conditions.

The relationship between position and inside temperature is confirmed by the graphs of figures 3 and 4 . In figure 3 the behaviour of sow C3 (both drip and snout cooling system) in relation to temperature is shown. The graph refers to 4 September when temperatures reached a maximum peak of $30.3^{\circ} \mathrm{C}$. In this day alert and dangerous conditions were found.

In the observed day, temperatures were not very high, especially early in the morning (the mean value from $0800 \mathrm{~h}$ to $1000 \mathrm{~h}$ was $23.31{ }^{\circ} \mathrm{C}$; from $0500 \mathrm{~h}$ to 0700 h was $23.62{ }^{\circ} \mathrm{C}$ ). THI indicates that the sow is in the 'neutral' thermal zone. Thank to these rather good thermal conditions the sow does not need to benefit from the fresh air and lies back in farrowing crate. But when temperature rises, during the central hours of the day (mean value from $1700 \mathrm{~h}$ to $1900 \mathrm{~h}$ was $30.16{ }^{\circ} \mathrm{C}$ ) the thermal conditions for the animals change. THI moves from comfort to alert and dangerous zones and the sow chooses to lie ahead: in this situation the fresh air coming out from the pipes is a valid help against the heat stress of the sows in farrowing room.

The graph of figure 4 shows similar behavioural patterns. This graph refers to a day (12 September) in the period from 10 to 20 days after farrowing. Temperatures were not very high during the day for a sudden storm ( $\max : 24.07{ }^{\circ} \mathrm{C}$; min: $21.78{ }^{\circ} \mathrm{C}$ ). Anyway sow B3 choose to lie ahead in the cage practically for all the time, except the central hours of the day. From $1500 \mathrm{~h}$ to $1900 \mathrm{~h}$ when the temperatures fall down, the sow changes position inside the crate, avoiding the air on the snout.

In conclusion it is possible to remark the considerable use of the system by the animals which can choose to profit or not from the air flow, according with the microclimatic conditions inside the farrowing room.

Moreover by table 3 we can observe that the sow (A2 - only drip system) shows clear signs of heat stress: it is very restless and changed position 71

\begin{tabular}{|l|c|c|c|c|c|c|}
\hline $\begin{array}{l}\text { Behavioural } \\
\text { patterns }\end{array}$ & A2 & B2 & C2 & A3 & B3 & C3 \\
\hline Lying Ahead & 49.96 & 80.45 & 80.80 & 87.64 & 73.32 & 67.52 \\
\hline Lying Back & 30.29 & 2.07 & 0.00 & 0.00 & 12.31 & 13.97 \\
\hline Nursing & 7.97 & 9.37 & 13.73 & 9.51 & 10.92 & 12.94 \\
\hline Standing & 6.75 & 5.34 & 2.72 & 1.15 & 0.32 & 2.40 \\
\hline $\begin{array}{l}\text { Feeding/ } \\
\text { Drinking }\end{array}$ & 1.91 & 2.20 & 2.09 & 0.98 & 3.26 & 2.21 \\
\hline Sitting & 3.11 & 0.58 & 0.65 & 0.73 & 0.86 & 0.95 \\
\hline
\end{tabular}

TABLE 3 - Behavioural patterns of sows in the second and third cycle; data referred to 4-8 days after farrowing (25-27 July; 4-6 September). 
times a day in average while the average datum of the other ones is 34 times in a day. The same sow remains in activity (standing or sitting) for a long time $(9.86 \%)$; the average of the other sows is $3.14 \%$.

The arrangement of the snout cooling system can bring some benefits even in terms of productive and reproductive performances. Although productive data were not collected, from our study it is possible to remark (table 4) that cooled sows spent more time nursing and feeding/drinking than the other sows. A loss of appetite and milk production is one of the first symptoms of heat stress.

Sows in the cage can lie down ahead in two different positions: with the nose or with the neck turned towards the outlet hole of the air pipe (fig. 5). The TV images allowed to define the position of the sows in the crate and how long they had lain down with the snout towards the air hole $(\mathrm{S})$ or with the neck $(\mathrm{N})$.

Behavioural results are reported in table 5. Cooled sows spend $71 \%$ of the total time lying with the snout turned towards the air outlet. In this way they show a clear pleasure in receiving the fresh air both on their nose and mouth. Anyway animals seem to appreciate receiving air in the neck zone as well $(21 \%$ of the total time). Probably in this second case the fresh air insists on a body part where the drops have already fallen, helping their evaporation and consequently improving the cooling of the animal. To well understand the graph it is important to notice that nursing activity has been included in the lying time.

In figure 6 the average values of BCS and fat thickness for the 31 sows are shown: nine sows with

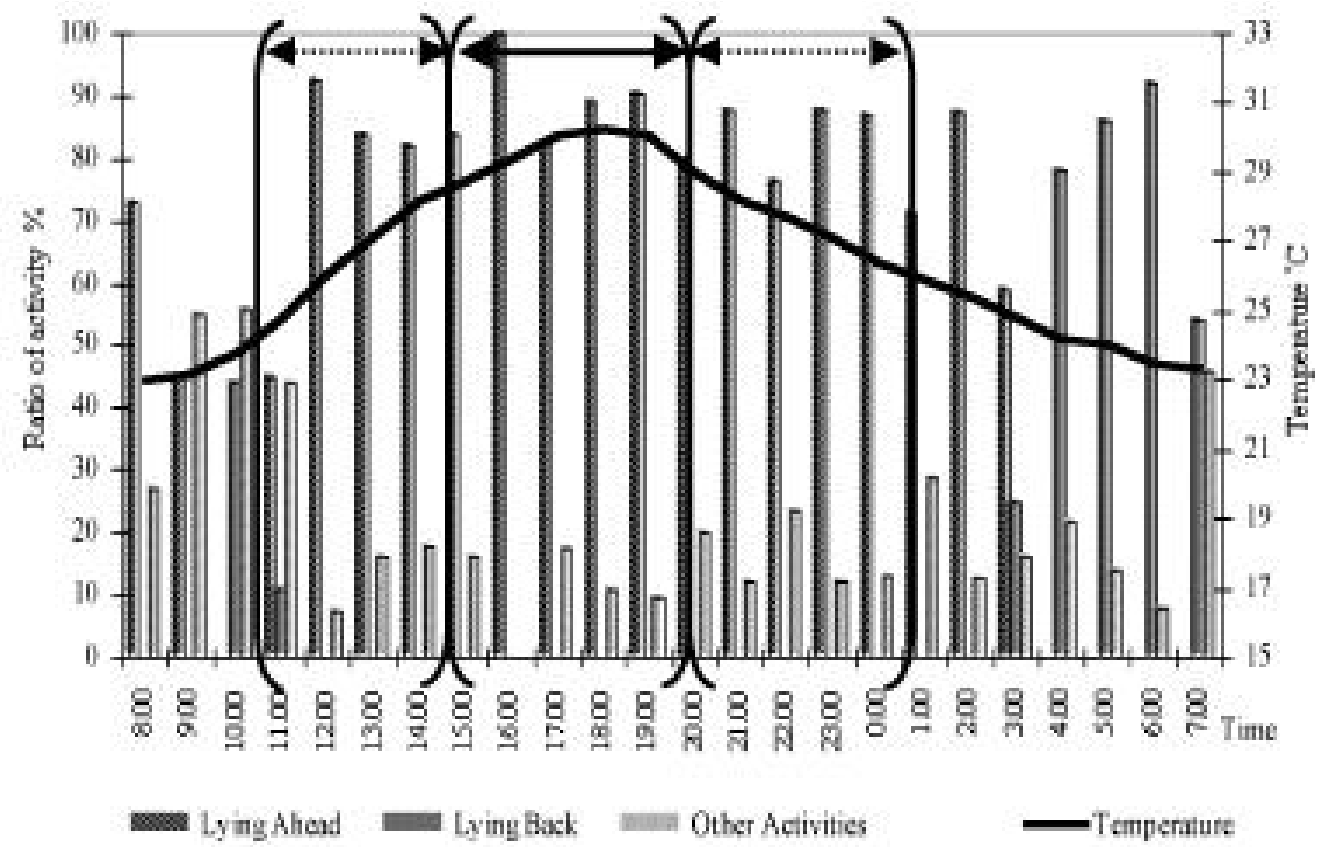

Fig. 3 - Relationships among behavioural patterns of sow "C3" refreshed both with drip and snout cooling (D-S), daily temperature and THI.

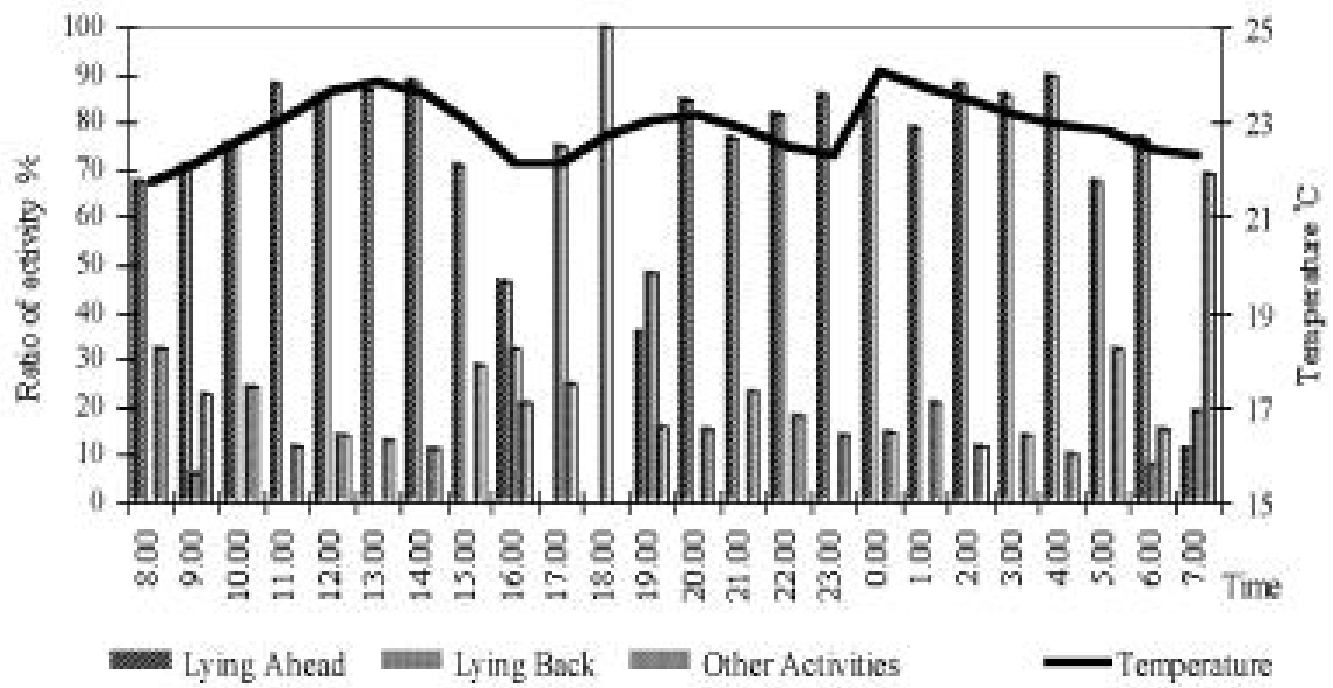

Fig. 4 - Relationships among behavioural patterns of sow "B3" refreshed both with drip and snout cooling (D-S), daily temperature and THI 


\begin{tabular}{|c|l|c|c|}
\hline \multicolumn{2}{|l|}{ Sow } & $\begin{array}{c}\text { Nursing } \\
\text { ratio } \\
(\%)\end{array}$ & $\begin{array}{c}\text { Feeding / } \\
\text { Drinking } \\
\text { ratio (\%) }\end{array}$ \\
\hline A2 & Drip only & 7.97 & 1.91 \\
\hline B2 & Drip and Snout & 9.37 & 2.20 \\
\hline C2 & Drip and Snout & 13.73 & 2.09 \\
\hline A3 & Drip only & 9.51 & 0.98 \\
\hline B3 & Drip and Snout & 10.92 & 3.26 \\
\hline C3 & Drip and Snout & 12.94 & 2.21 \\
\hline
\end{tabular}

TABLE $\quad 4$ - Time for nursing and feeding-drinking of sows.

drip cooling only (D); 12 sows with both drip cooling and snout cooling (D-S); and 10 sows with drip cooling and a full metal sheet under the body (D-F). The fat thickness reductions and the BCS worsening during the lactating phase in relation to the adopted systems were not significant. The insufficient uniformity of the sows at farrowing during the experimental activity did not allow the collection of significant statistical data. On average the fat thickness reduction is very similar in the three compared systems (1.89; $2.00 ; 1.90$ for experiments D, D-S and D-F, respectively). The same consideration is valid also for BCS values, but for solution D-F (drip cooling and full steel floor) the mean decrease of BCS is lower.

The body and skin temperatures of the sows did not show significant differences in relation to the choice of cooling system. In the three cycles, three different experiments were conducted on 48 sows, in the hottest hours of afternoon, with inside air temperature from $27.2^{\circ} \mathrm{C}$ to $31.0^{\circ} \mathrm{C}$. The body and skin temperatures were measured $30 \mathrm{~min}$ before starting the drip system, after $30 \mathrm{~min}$ from the beginning of water supply, and after $30 \mathrm{~min}$ from the end of water supply.

The rectal temperatures were on average $39.04^{\circ} \mathrm{C}( \pm$ $0.94), 39.06^{\circ} \mathrm{C}( \pm 0.92)$ and $39.03^{\circ} \mathrm{C}( \pm 0.92)$ respectively in the three described situations. Therefore, the rectal temperatures are not influenced by the drip cooling for only $30 \mathrm{~min}$. However the skin temperature measured at $0.20 \mathrm{~m}$ from the tail junction (area not wetted by water) had a fairly good drop: from a mean
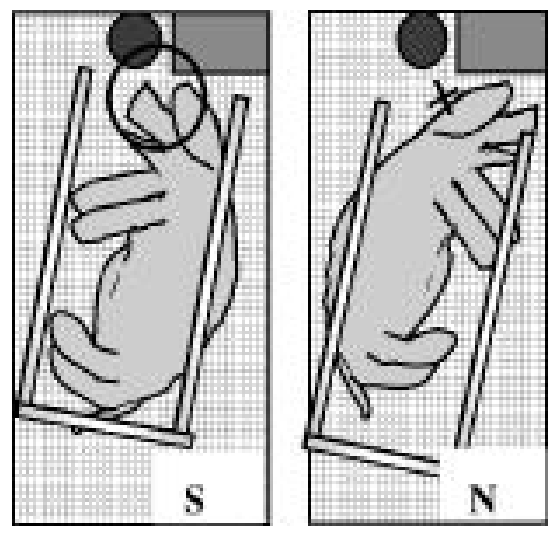

Fig. 5 - Farrowing cage: view of the air fresh hole (on the left); pattern of the two possible 'ways' of receiving the fresh air from pipe, on snout $(\mathrm{S})$ or on neck $(\mathrm{N})$.

\begin{tabular}{l|c}
\hline Behavioural patterns & $\%$ \\
\hline Lying Ahead S & 71.03 \\
\hline Lying Ahead N & 21.44 \\
\hline Lying Back S & 0.79 \\
\hline Lying Back N & 0.00 \\
\hline Sitting & 0.73 \\
\hline Standing & 4.09 \\
\hline Feeding/Drinking & 1.92 \\
\hline
\end{tabular}

TABLE 5 - Average behavioural patterns of the cooled sows of the second and third cycle (B2, C2, B3, C3) regarding the lying position in relation to the air outlet hole (S: Snout; N: Neck). Data were collected during the hottest hours of the day $(1600 \mathrm{~h}-2000 \mathrm{~h})$

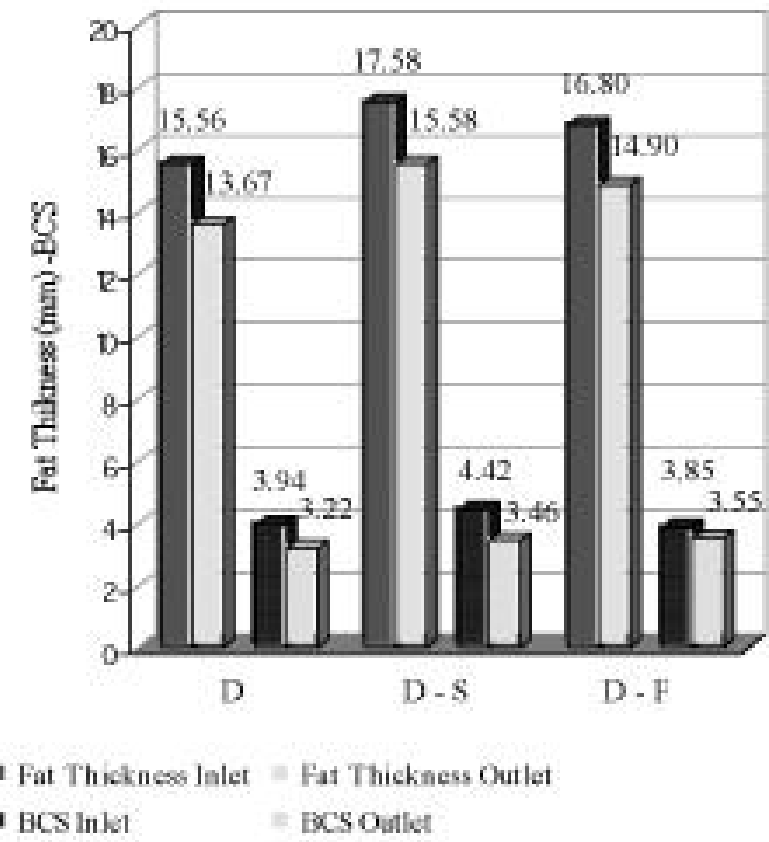

Fig. 6 - Fat thickness and BCS of sows at inlet into farrowing room and outlet (D: drip cooling; D-S: drip and snout cooling; D-F: drip cooling and full metal floor).

value of $36.48^{\circ} \mathrm{C}$ before the water supply the value decreased to $36.03^{\circ} \mathrm{C}$ after $30 \mathrm{~min}$ from the beginning of the drip cooling. The value after $30 \mathrm{~min}$ from the end of water supply increased a little $\left(36.10^{\circ} \mathrm{C}\right)$.

\section{Conclusions}

On the basis of experimental trials some conclusions can be drawn about the planning of cooling solutions in farrowing rooms, referred to areas characterized by a wet hot weather, such as the Po Valley in Italy.

- In the farrowing rooms temperatures often reach high peaks and THI index represents thermal conditions of 'dangerous', 'alert' and 'emergency' for the animals. 
- In these conditions it becomes very helpful to arrange systems for heat protection of the sows housed in single crates. It is particularly important to provide the sows with an effective cooling system when uncomfortable floors are used, such as the plastic ones.

- During the trials the effectiveness of the compared cooling treatments with regard to productive parameters was not pointed out. However the behavioural analysis remarked a different influence of the examined cooling systems on the animal welfare.

- Nevertheless the data on skin temperatures showed a positive effect of drip cooling.

- The combined system of drip and snout cooling seems to be appreciated from the sows, more than the single systems. Therefore the combined system can be considered effective in the reduction of heat stress. The sows seem to appreciate the air flow provided by snout cooling ducts in the front area of the farrowing crate. The sows remained for long periods with the snout or the neck near the air outlet hole. With long enough farrowing crates $(2.50 \mathrm{~m})$ the sows could freely move back, lying in such a position as to optimize the effects of the cooling systems.

- The piglets do not present any problem for the air flow, if directed to the part of the crate diametrically opposed to the heat nest.

- The usefulness of the full metal floor of $0.50 \mathrm{x}$ $0.60 \mathrm{~m}$, placed under the head of the sow, was not proved by productive parameters. However the full metal plate seems to be appreciated thanks to the continuous wetting: the floor remains wet for long periods after the water supply and the sow is able to dissipate a higher heat quantity from the wet body surface.

In the end the present study allowed us to give a preliminary evaluation of the main cooling systems for the sows in farrowing rooms. Useful elements have been collected to plan further scientific experiments on a large scale, in order to verify the preliminary results.

\section{References}

[1] BARBARI M., Raffrescamento a goccia su scrofe allattanti e gestanti, Rivista Suinicoltura (1991) 4, 49-55.

[2] Barbari M., Sorbetti Guerri F., Cooling systems for heat protection of farrowing sows, Proc. $7^{\text {th }}$ Intern. Symposium Livestock Environment (2005) Beijing, 18-20May, 122-129.

[3] Bull R.P., Harrison P.C., Riskowski G.L., GoNYOU H.W., Preferences among cooling systems by gilts under heat stress, J. Animal Science (1997) 75, 20782083.

[4] Cox N.M., Britt J.H., Armstrong W.D., Alhusen H.D., Effect of feeding fat and altering weaning schedule on rebreeding in primiparous sows, J. Animal Science (1983) 56, 21.

[5] Dong H., TAO X., Lin J., XIN H., Comparative evaluation of cooling systems for farrowing sows. Trans. ASAE (2001) 17 (1), 91-96.

[6] Esmay M.L., Dixon J.E., Environmental control for agriculture buildings. AVI Publishing Company Inc. (1986) Westport, CT 06881.

[7] Harp S.L., HuhnKe R.L., Drip vs. wetted-pad evaporative cooling of farrowing houses in Oklahoma. Trans. ASAE (1991) 7 (4), 461-464.

[8] Heard L.R., Froehlich D.P., Christiansons L.L., WoERMAN R., WitMER W., Snout cooling effects on sows and litters. Trans. ASAE (1986) 29 (4), 1097-1101.

[9] INGRAM D.L., Evaporative cooling in pigs, Nature (1965) 207, 415-416.

[10] Lucas E.M., Randall J.M., Meneses J.F., Potential for evaporative cooling during heat stress periods in pig production in Portugal (Alentejo), J. Agri. Eng. Res. (2000) 76, 363-371.

[11] McGlone J.J., Stansbury W.F., Tribble L.F., Management of lactating sows during heat stress: effects of water drip, snout coolers, floor type and a high energy-density diet. J. Animal Science (1988) 66, 885-891.

[12] MERKEL J.A., Zone cooling for lactating sows, M.S. Thesis (1965) Ames, Iowa State University.

[13] RaAP D.L., Froehlich D.P., Julson J.L., Woerman R., Zone and drip cooling comparisons for lactating swine. Trans. ASAE (1988) 31 (6), 1774-1781.

[14] Stansbury W.F., MC Glone J.J., Tribble L.F., Effects of season, floor type, air temperature and snout coolers on sow and litter performance. J. Animal Science (1987) 65, 1507.

\section{SUMMARY}

A preliminary evaluation of different cooling systems for farrowing - lactating sows was conducted in a pig farm in the North of Italy.

In an experimental farrowing room 16 crates were used to study different cooling solutions during three cycles of observations. The evaluated systems were: drip cooling (five crates), drip and snout cooling (six crates), drip cooling and a full steel sheet placed under the body of the sow (five crates).

Rectal and skin temperatures were measured during hot hours of the day. Fat thickness was measured and body condition score of the sows was estimated at the beginning and at the end of the lactating period.

A closed-circuit television system was also installed to collect information about the behaviour of the sows cooled with the drip system or with both drip and snout cooling system.

While differences concerning body and skin temperatures as well as BCS and fat thickness were not significant, the behavioural patterns showed how the sows appreciated the contemporaneous use of the drip and snout cooling methods. The sows preferred to lie with the snout towards the air outlet especially during the hottest hours of the day.

In order to obtain the best thermal conditions inside the farrowing crate, the drip system had to be coupled with the snout cooling system and the full metal floor placed under the head of the sows.

Further studies are necessary to confirm the preliminary obtained results.

\section{Key words:}

Drip cooling, snout cooling, lactating sows, farrowing room. 